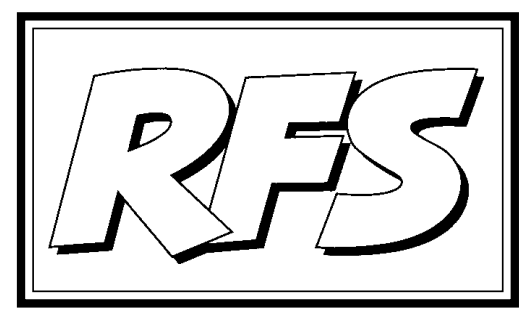

Revista de Fomento Social, 56 (2001), 143-151

\title{
Entre Escila (inflación) y Caribdis (recesión)
}

J avier Gorosquieta SJ ${ }^{*}$

\section{Introducción}

Nos encontramos ahora, en la economía internacional, en un grave riesgo o dilema parecido al que tenían los clásicos romanos de caer, navegando por el Mediterráneo junto al estrecho de Mesina, en uno de los dos abismos o peligrosos vórtices marinos que se cernían a derecha e izquierda de la nave: Escila y Caribdis. Los extremos de este dilema tienen hoy otro nombre: inflación a la derecha, recesión a la izquierda. El arte del político de la economía está hoy en lograr conducirla por el centro, por la fortaleza y la salud, soslayando esas dos graves enfermedades. Más en concreto: mantenerse o volver a lo que ha sido realidad durante diez años consecutivos en los Estados Unidos: fuerte crecimiento y creación de empleo en una gran estabilidad de los precios y en el equilibrio o superávit presupuestario. De la economía española se puede decir lo mismo para el período 1995-2000, aunque el punto de partida haya sido una muy grave situación de paro,

* Estando ya en prensa este original recibimos la triste noticia del fallecimiento de Javier Gorosquieta el 10 de abril pasado en Bilbao. Descanse en paz. Véase su necrológica al comienzo del presente número. 
necesite por ello impulsar todavía más la creación de puestos de trabajo y el equilibrio presupuestario se vaya logrando de manera progresiva. Algo parecido ha sucedido con el conjunto de la Unión Europea (UE), aunque con un ritmo de crecimiento, como media, menor que el nuestro, y, por el contrario, una cifra inicial de paro, también como media, menor. El pacto de estabilidad presupuestaria de la UE completa el panorama.

De todas maneras no queremos decir que la situación de la economía occidental en estos últimos años haya sido la suma de todos los bienes sin mezcla de mal ninguno. No. Las sombras en la economía estadounidense han sido, sobre todo, un muy grave incremento de las desigualdades sociales y de la pobreza, más los salarios basura. Lacras en la economía española siguen siendo el paro, como queda dicho, la precariedad laboral, la insuficiencia del seguro de desempleo, la discriminación de género. Respecto de la UE, también lo son el paro y la relativa debilidad del crecimiento. $Y$ hay una especie de pecado original de Occidente, el olvido egoísta del mundo en desarrollo, particularmente de África.

No bastan, pues, las puras variables económicas, pero éstas son la base que permite superar asimismo todos los déficits sociales.

\section{Se presenta la inflación}

Cuando en enero de 1999 el precio internacional del petróleo estaba en los diez dólares por barril se comenzó a hablar del riesgo de una recesión económica en la economía occidental y mundial. Había sido tan exitosa la lucha contra la inflación, los tipos de interés estaban tan bajos, que ya se trataba abiertamente del peligro de una deflación. Los tipos de interés prácticamente no podían bajar más para alentar la economía, la estabilidad de los precios era casi total, de tal forma que se temía que el próximo movimiento de estos últimos fuera su caída, con el consiguiente efecto de la disminución de beneficios, y del desaliento en la creación de empresas y del concomitante empleo: un movimiento acumulativo en la vertiente hacia una verdadera recesión o deflación. Tan exitosa fue, hasta ese momento, la lucha antiinflacionista.

En aquella fecha estábamos saliendo de la crisis económica mundial de los años 1997 y 1998, que tuvo su origen en el Sudeste asiático y que se cebó especialmente en J apón, en algunos países emergentes como Brasil o Argentina y en otros en transición político-económica como Rusia. Apenas hizo

\section{RFS}


mella en los países desarrollados, con la excepción de Japón. Pero había mucho temor al contagio universal.

Ambos miedos comenzaron a hacer pensar en una deflación o depresión generalizada. Corrió mucha tinta sobre el particular. Uno de los libros más leídos sobre el tema fue el del profesor del M.I.T. estadounidense, Paul Krugman, «El Retorno de la Economía de la Depresión»]. Defiende en el mismo la necesidad de una vuelta a una «economía de la demanda»: estimular la demanda en los mercados, incluso con políticas keynesianas de incrementar el gasto público, aun incurriendo en déficits presupuestarios y, desde luego, perder bastante el miedo a la inflación: programar deliberadamente una inflación «reptante», lenta, moderada, de entre un $2 \%$ y un $4 \%$. ¿Para qué? Para que la subida de los precios finales de venta mejorara las expectativas empresariales de beneficio, y se lograra, como consecuencia, el promover las inversiones empresariales, la creación de empleo y la salida, en definitiva, de la depresión.

Nos habíamos olvidado ya de esta manera de pensar. Se trataba de un mundo de ideas anterior a la situación que comenzó en Occidente y en el mundo entero con la crisis del petróleo que se inició en 1973. En aquel mundo de ideas las crisis solían ser, efectivamente, crisis de demanda y la vía de salida estaba, efectivamente, en el estímulo general del consumo.

Pero en el otoño de 1973 las cosas cambiaron con la llegada del primer «shock» petrolero. Aumentaron fuertemente los precios de la energía, y cuando los empresarios intentaron trasladar a los precios finales de venta su inflación de costes, se encontraron con que el mercado reaccionaba, no encajando las subidas, sino comprando menos. Con lo cual, y porque los empresarios no producían para quedarse con la mercancía sino para darle salida en el mercado, consecuencia de aquella inflación de costes fue el desaliento de las iniciativas empresariales, de los volúmenes de producción y de la creación de empleo. Dimos con el extraño fenómeno de la stagflación, inflación de costes con estancamiento de la economía. De ahí que naciera, o que al menos se diera mucho relieve, a la llamada «economía de la oferta»: salir de la stagflación con reformas estructurales desde el lado productivo; una de estas reformas importantes tendría que ser la que permitiera el ahorro de energía, particularmente de petróleo, en el proceso productivo.

1 P. Krugman, (2000), El Retorno de la Economía de la Depresión. Edición española en Barcelona, Editorial Crítica. 
Así estuvimos luchando hasta 1985 en que se consolida un periodo de prosperidad en la economía internacional, con precios del petróleo más moderados, una industria de ahorro de energía muy desarrollada y una inflación tolerable.

En tiempos de la stagflación hubiera sido un disparate aplicar las estrategias parecidas a las antes señaladas de Paul Krugman. Lo intentó, p.ej., la Francia de un Mitterrand recién llegado al poder en 1981, pero tuvo que rectificar drásticamente antes de que pasara un año; sus políticas de demanda no lograron sino disparar la inflación y el desempleo, incrementar gravemente el déficit fiscal y también el de la balanza de pagos. Lo intentó también el Gobierno español entre 1973 y 1975, creyendo que la crisis del petróleo sería pasajera; la consecuencia fue que España perdió dos años preciosos de lucha contra la crisis, y por ello tardó en salir de ella más que los otros países de su entorno europeo, aparte de sufrir un incremento bastante mayor del desempleo.

Pero ¿han llegado los tiempos de volver a la «economía de la demanda»?

Krugman escribía, como decíamos, a primeros de 1999. Entonces los precios del petróleo estaban en los mencionados diez dólares el barril. Y sucede que, desde esa fecha hasta noviembre de 2000, los precios del crudo escalaron la cumbre de los 36 dólares. Acontece también que, como consecuencia de la mayor potencialidad demostrada por la economía estadounidense respecto de la europea, la moneda común de doce miembros de la UE, entre los que se cuenta España, el euro, se fue depreciando respecto del dólar: cayó de valer de salida 1,16\$ a sólo 0,82\$ en noviembre de ese año. Como las importaciones de petróleo se pagan en dólares, ambos fenómenos, la subida del crudo y la depreciación del euro, dispararon los precios de las importaciones del oro negro. De ahí se trasladó la carestía a los combustibles derivados; de ahí a las tarifas de transporte, a la industria, y a los servicios consumidores de esos derivados, al consumo doméstico de gasoil y de ahí a todos los precios. Estábamos ya lejos de la depresión amenazante de que hablaba Krugman y otros muchos con él. Estábamos, por el contrario, entrando en la enfermedad de réplica: la inflación.

Pero a lo largo de 1999 y de los once primeros meses de 2000 esta nueva crisis de inflación contó con un gran aliado para no caer de nuevo en la stagflación: con una demanda o consumo boyante. Por eso las empresas en general pudieron seguir mostrando beneficios sanead os y como consecuencia siguió, en concreto en España, un fuerte ritmo de creación de empleo: 
unos 600.000 nuevos puestos de trabajo creados en 2000. De ahí que se pueda volver hoy, de alguna manera, a aquel modo de pensar: perdamos un poco el miedo a la inflación con el fin de estimular el crecimiento y la creación de empleo. Naturalmente que se piensa en aquella inflación moderada, entre un $2 \%$ y un $4 \%$ de alza del nivel de precios, estimado según el Índice de Precios al Consumo (IPC). Tanto el Banco Central Europeo como el Gobierno español se plantean para el 2001 un horizonte de subida de los niveles de precios en el entorno del $2 \%$ como estimulante de la economía; a partir de ahí el conveniente estimulante se convertiría en verdadera droga. Y no queremos, naturalmente, una economía drogadicta.

Desde primeros de diciembre cambió de nuevo el horizonte. Como consecuencia de un otoño de suaves temperaturas en Europa y del incremento de la oferta de petróleo por parte de los países productores, aparecieron unas existencias muy sustanciosas de crudo en los mercados. Y ahí comenzó el declive de sus precios: desde aquellos $36 \$$ barril a sólo $24 \$$. Por otra parte, la economía estadounidense, como veremos después, comenzó a dar señales de desaceleración, de un cierto desfallecimiento. Esto revalorizó el euro respecto del dólar hasta alcanzar el tipo de cambio un euro 0,95\$. Ambas realidades abarataron la compra de crudo, lo cual está siendo un arma muy fuerte contra la inflación desbocada: en España un 4\% de subida del IPC en 2000. Y ello hace que podamos mirar aquí al 2001 con cierto optimismo en materia de estabilidad de los precios: posibilidades fundadas de volver a un IPC, estimulante, en el entorno del $2 \%$.

\section{Recesión}

Acabamos de decir que en la economía estadounidense se observan ciertos indicios de desfallecimiento. Las ventas navideñas de 2000, por ejemplo, cayeron significativamente; algo parecido sucede con el mercado del automóvil (stocks muy abundantes y despidos masivos).

Para encontrar las causas de este, de momento, «aterrizaje suave» de la economía USA es fundamental acudir al proceso desalentador de las bolsas de valores americanas en el año 2000 . Efectivamente, un $49 \%$ de las familias americanas son hoy propietarias de acciones, bien directamente, bien a través de fondos de las mutualidades o de planes de pensiones, comparadas con el $4 \%$ en 1952. Cuando las cotizaciones suben los americanos se sienten opulentos. En 1999, cuando el índice de la bolsa de Nueva York ganó un 25\% 
y el índice de los valores tecnológicos Nasdaq un 85\%, los patrimonos familiares crecieron en 5,5 billones de dólares. Este «efecto riqueza» se transforma en un mayor consumo. La verdad es que de cada dólar adicional en sus carteras los americanos gastan de 3 a 5 centavos. Este ingreso discrecional es crítico, fundamental: el gasto en bienes y servicios de consumo constituye casi los dos tercios de la actividad económica USA.

El «efecto riqueza» ha sido una fuerza de la Nueva Economía, pero ahora aparece el lado contrario. Cuando las cotizaciones caen golpea un negativo «efecto riqueza». Aparecen los malos datos en la confianza del consumidor. Lo que pone nerviosa a la gente es ver caer en picado sus carteras de acciones. Desde que el Dow Jones alcanzó una cima en enero de 2000 y el Nasdaq en marzo se han esfumado más de 2,5 billones de dólares. Y precisamente, así como los inversores compran más bienes y servicios cuando la tendencia de las bolsas es alcista, compran menos ahora tras el varapalo recibido en el año $2000^{2}$. Es decir, que la clave para explicar el «debilitamiento progresivo ${ }^{3}$ de la economía USA desde noviembre pasado hasta ahora es el retraimiento del consumo.

Si las bolsas mejoran en el 2001 el consumo volverá a tirar con fuerza de la economía hacia el crecimiento. «Si el pueblo pierde la confianza, podemos tener un periodo de recesión», decía en enero una ex-dirigente de la Reserva Federal. Pero ¿mejorarán?

Tras tres años de crecimiento, de alzas casi ininterrumpidas, el propio Alan Greenspan advirtió, a finales de 1999, que las bolsas estaban mostrando una «exuberancia irracional». Esto quiere decir que, a primeros de 2000 las bolsas, en general, estaban claramente sobrevaloradas. Por eso, en buena parte, la caída del año 2000 ha sido, de al gún modo, un proceso de saneamiento, de volver la cotización de los valores a niveles más racionales. Ahí nos encontramos ahora. Pero probablemente los inversores, escarmentados, tardarán algo en volver a una cierta euforia compradora en toda clase de mercados de bienes y servicios, y, por lo tanto, nos hemos de preparar para un periodo de desaceleración, que algunos llaman recesión, de la economía USA. Les convendrá, por ello, estimular la demanda, de acuerdo con la ortodoxia económica clásica antes aludida.

2 Estos datos están tomados de la revista TIME, Vol.157, o 1, 8-1-01, pp. 14-18.

3 Expresión empleada por Alan Greenspan, presidente de la Reserva Federal, en su comunicado del 23 de diciembre pasado. 
En España, a 24 de diciembre de 2000, la bolsa española valía 6,16 billones de pesetas menos que al comienzo del año. Un dinero que ha desaparecido con la caída del precio de los valores. En el selectivo índice lbex 35, que recoge la cotización de las 35 mayores empresas en bolsa, sólo doce de esas empresas han conseguido una ganancia, mientras que el resto soporta pérdidas en muchos casos abultadas. Prácticamente to dos los grupos se ven salpicados por el signo negativo. Bancos, eléctricas, telecomunicaciones $y$, cómo no, los valores de la llamada Nueva Economía, que tras un primer trimestre brillante, no han hecho otra cosa que caer.

De esta pérdida de valor bursátil, a las familias les corresponde 2,15 billones de pesetas, ya queellas son propietarias de aproximadamente el $35 \%$ de las acciones que se negocian en el mercado. Un dinero que se ha dejado de ganar, que estaba ahí latente a principios de 2000 y que en gran parte se había generado en los anteriores ejercicios de bonanza en el mercado.

Un capitalismo popular en el que muchos han buscado el complemento del sueldo anual o un dinerillo con el que cambiar de coche o pasar unas vacaciones inolvidables. ¿Quién no conoce a un familiar, amigo o a sí mismo, que se ha visto atraído por las fuertes ganancias que ha registrado la bolsa en los últimos años? El año 2000, sin embargo, ha frustrado esta posibilidad, en una bolsa que llevaba desde 1995 subiendo de forma ininterrumpida ${ }^{4}$.

Según datos de la bolsa de Madrid, cerca de 8 millones de españoles tienen intereses en la renta variable y, por tanto, no son ajenos a las subidas y descensos como el actual.

¿Habrá que temer entonces en España una recesión con la misma fuerza con que la temen ahora en Estados Unidos? Creo que no. Y la razón es que la realidad muestra que el consumo, la demanda de bienes y servicios, en España tira también ahora con fuerza hacia arriba de la economía. No se produce aquí el «efecto riqueza» negativo de que hablábamos al tratar de la economía USA, no se produce aquí, quiero decir, con la misma fuerza que en USA por la sencilla razón de que el porcentaje de inversores en bolsa es mucho menor aquí que allá. Por eso, al contrario de lo que ocurre en Estados Unidos, no tenemos aquí necesidad perentoria de despertar el consumo, porque la demanda de bienes y servicios está aquí muy en vigilia. Podemos evitar la recesión.

4 Cfr. diario EL PAÍS, 24 de diciembre de 2000. 


\section{La Reserva Federal}

Siguiendo con su política antiinflacionista la Reserva Federal norteamericana subió varias veces los tipos de interés a lo largo de los once primeros meses del año 2000. Está claro lo que se pretende con la medida: encarecer tanto la financiación de las empresas como los créditos al consumo. La carestía de los créditos a las empresas enfría la euforia empresarial, se desacelera con ello el crecimiento económico, se generan, por lo tanto, menos ingresos procedentes de las empresas; estos menores ingresos se traducen en menor entusiasmo por el consumo; la demanda finalmente, en consecuencia, presiona menos al alza los niveles de precios. En cuanto a los créditos al consumo, si se encarecen, lo normal es que se demanden menos y que también por este camino no incrementen la demanda de bienes y servicios de consumo y dejen de presionar al alza sobre los niveles de precios.

Pero llegó el 23 de diciembre, cuando ya se hablaba abiertamente en USA de «aterrizaje suave» de la economía, si no claramente de recesión. Y los mercados esperaban, en consecuencia, un cambio radical de política en materia de tipos de interés, una rebaja, en definitiva. La Reserva Federal decidió solamente mantener los tipos de interés en su nivel de entonces, el $6,5 \%$. Los mercados acogieron muy mal esta decisión; las bolsas cayeron casi en picado. Los mercados interpretaron que Greenspan se había equivocado esta vez. Y la atonía bursátil, a bajos niveles de cotización, se instaló en los mercados.

Primeros de enero de 2001. Por sorpresa la Reserva Federal baja medio punto los tipos de interés. Un viraje de 180 grados. Rectifica. Y los mercados bursátiles acogen esta decisión con euforia. Esto significa que los mercados USA interpretan que, efectivamente, una cierta recesión se ha instalado en aquel país y que la política propia de la «economía de la depresión» será la apropiada en Estados Unidos durante el 2001.

En España y en la UE ya hemos dicho que las cosas cambian, en concreto porque el «efecto riqueza» negativo no es ni tiene por qué ser aquí tan fuerte como al otro lado del Atlántico. Aquí, con unos precios del petróleo en torno a los $25 \$$ barril y un euro en la cercanía de la paridad con el dólar, podemos volver a las condiciones del feliz cuatrienio 1995-1999. Se notará aquí, desde luego, el menor pulso de la primera economía mundial, Estados Unidos, p.ej. en forma de menores exportaciones a aquel país, pero esto no afectará esencialmente al crecimiento, a la creación de empleo, a una inflación en el

\section{RFS}


entorno del $2 \%$ y a la estabilidad fiscal.

¿Tendrá que pasar, de todas maneras, el BCE de la política monetaria antiinflacionista a la política antirecesiva? Pudiera ser, con cautela, para estimular todavía más la creación de empleo, es decir, la eliminación del problema socioeconómico más importante con que se enfrenta la UE en este momento y desde el inicio de la primera crisis del petróleo en el otoño de 1973.

\section{Conclusiones}

Escribo estas «conclusiones» a 20 de febrero, mes y medio después de la primera redacción de este artículo. Y si alguna conclusión se puede sacar ahora es que ha aumentado la incertidumbre. Se confirma en USA una recesión más dura que la del «aterrizaje suave». Como consecuencia, la Reserva Federal volvió a bajar en medio punto el tipo de interés. El precio del barril de petróleo ha vuelto a subir hasta los 29-30 \$, debido a la decisión de la OPEP de reducir la producción y a la inseguridad sobre las exportaciones petrolíferas de Irak. El euro, mientras tanto, se ha vuelto a devaluar hasta el entorno de los $0,92 \$$, sin duda porque las alzas del petróleo afectan más a los doce países del euro dentro de la UE que al rico en petróleo propio Estados Unidos. Los expertos más solventes se arriesgan a vaticinar un movimiento de la economía USA, y de alguna manera también, por lo tanto, de la mundial, en forma de «V»: una recesión a lo largo, más o menos, de los próximos seis meses, y una recuperación, de la misma manera, progresiva y rápida. Entonces, para ser consecuentes con todo lo arriba escrito, lo conveniente sería una política antidepresiva, por ahora, para ir pasando a otra mas bien antiinflacionista desde el inicio de la esperada recuperación. Esto parece claro respecto a los Estados Unidos; en principio, también, respecto de Europa, pero sólo en tanto en cuanto ésta vaya siguiendo, como es probable, la pauta de esas dos fases del ciclo estadounidense. 